\title{
Depression and peripheral artery disease: why we should care and what we can do
}

\author{
Joel L. Ramirez ${ }^{1}$ and S. Marlene Grenon ${ }^{1,2^{*}}$
}

\section{To the Editor}

Peripheral artery disease (PAD) is a global problem that has been estimated to affect more than 200 million people worldwide with increasing disease incidence (Fowkes et al. 2013). Patients with PAD experience a dramatically high risk of adverse cardiovascular events and mortality, as well as impaired quality of life due to claudication symptoms, limb loss, and physical disability. Although several traditional risk factors for PAD have been identified, a more comprehensive understanding of the factors that may influence the development and progression of PAD is essential in order to adequately care for this high-risk patient population.

Recent evidence suggests that depression may represent an under-recognized risk factor for PAD. Although the relationship between depression and other atherosclerotic diseases such as coronary artery disease (CAD) is better understood and supported by robust evidence (Elderon and Whooley 2013), our understanding of how depression may affect PAD remains more limited. However, previous evidence linking depression with CAD suggests several plausible mechanistic pathways through which depression may be associated with PAD. These mechanisms include dysregulation of the hypothalamic-pituitary-adrenal axis, autonomic system, immune system, endothelial function, and coagulation cascade, as well as an increased prevalence of several behavioral risk factors associated with atherogenesis, including tobacco use, physical inactivity, and medical non-adherence (Ramirez et al. 2018).

Recent work focused on patients with PAD has begun to highlight the impact that depression may have on this patient population (Ramirez et al. 2018). Patients in the community who develop PAD have been reported to have a higher prevalence of depressive symptoms, and diagnoses of depression have been associated with incident PAD (Wattanakit et al. 2005). McDermott et al.

\footnotetext{
* Correspondence: marlene.grenon@ucsf.edu

${ }^{1}$ Department of Surgery, Division of Vascular and Endovascular Surgery, University of California, San Francisco, CA, USA

${ }^{2}$ Vascular Surgery Section, Veterans Affairs Medical Center, Mail Code 112G, 4150 Clement St, San Francisco, CA 94121, USA
}

reported in a cross-sectional analysis of The Walking and Leg Circulation Study the presence of depression or depressive symptoms in $19.6 \%$ of patients with PAD, but only in $13.2 \%$ of patients without PAD $(p=0.003)$ (McDermott et al. 2016). Among patients with pre-existing PAD, depression has been associated with impaired physical function (Smolderen et al. 2008; McDermott et al. 2003; Ruo et al. 2007), increased mortality (McDermott et al. 2016), worse revascularization patency and recurrence of symptoms after peripheral revascularization (Cherr et al. 2007), increased risk of major amputation (Arya et al. 2018), and increased progression of PAD (Cherr et al. 2008). However, patients with pre-existing PAD are also more likely to develop depressive symptoms (McDermott et al. 2016), suggesting that the relationship between PAD and depression may be bi-directional.

Although the directionality of this relationship remains unclear, the evidence linking these two diseases is undeniable. As endovascular and vascular specialists, we carry the responsibility of treating and preventing PAD. As such, recognizing depression as an important risk factor for poor outcomes in patients with PAD is essential to providing the highest quality care. Although there are currently no guidelines available that address the screening, diagnosis, and management of depression among patients with PAD, guidelines do exist for patients with CAD (Lichtman et al. 2008) and may be generalizable to those with PAD. These guidelines include screening for depression using the two or nine item Patient Health Questionnaire (PHQ), and referring patients to a mental health specialist when appropriate. However, no studies to date have examined the effect of treating depression on the progression of PAD or outcomes among patients with PAD.

Further research is warranted to more comprehensively understand the relationship between depression and PAD. This includes an understanding of depression's physiologic implications on peripheral atherogenesis, vascular injury, and recovery after surgical or endovascular interventions. We strongly encourage investigators conducting research in patients with PAD to collect information on mental health comorbidities and treatment. We recommend 
collecting data related to mental health diagnoses and/ or eliciting a brief psychiatric history, documenting psychiatric medications, and screening for depression using validated questionnaires, such as the PHQ-9. Doing so would not only provide valuable evidence to further characterize the relationship between depression and PAD, but also has the potential to aid in the development of management guidelines to improve the outcomes of patients with comorbid depression and PAD. As the global population ages and the incidence of PAD increases, properly recognizing and treating all of the risk factors associated with PAD will become essential to reducing the burden of this disease.

\section{Funding}

This project was supported by the National Center for Advancing Translational Sciences, National Institutes of Health (NIH), through University of California, San Francisco-Clinical and Translational Science Institute Grant Number TL1 TR001871 with additional student research support from the Society for Vascular Surgery Student Research Fellowship Award and the American Heart Association Student Scholarship (JLR). Furthermore, this work was supported by start-up funds from the University of California, San Francisco and the Northern California Institute for Research and Education, by Award Number KL2RR024130 from the National Center for Research Resources, Award Number 1K23HL122446-01 from the NIH/ National Heart, Lung, and Blood Institute, and a Society for Vascular Surgery Seed Grant and Career Development Award (SMG). The content is solely the responsibility of the authors and does not necessarily represent the official views of the National Center for Research Resources, NIH, Society for Vascular Surgery, or the American Heart Association. The funding organizations were not involved in the design and conduct of the study, collection, management, analysis, and interpretation of the data, or preparation, review or approval of the manuscript.

\section{Availability of data and materials}

Data sharing not applicable to this article as no datasets were generated or analysed during the current study.

\section{Authors' contributions}

Conception and design: JLR, SMG, Writing the article: JLR, Critical revision of the article: JLR, SMG, Final approval of the article: JLR, SMG, Overall responsibility: SMG.

\section{Ethics approval and consent to participate}

Not applicable.

\section{Consent for publication}

Not applicable.

\section{Competing interests}

The authors declare that they have no competing interests.

\section{Publisher's Note}

Springer Nature remains neutral with regard to jurisdictional claims in published maps and institutional affiliations.

Received: 13 April 2018 Accepted: 28 May 2018

Published online: 18 September 2018

\section{References}

Arya S, Lee S, Zahner GJ et al (2018) The association of comorbid depression with mortality and amputation in veterans with peripheral artery disease. J Vasc Surg. https://doi.org/10.1016/j.jvs.2017.10.092

Cherr GS, Wang J, Zimmerman PM, Dosluoglu HH (2007) Depression is associated with worse patency and recurrent leg symptoms after lower extremity revascularization. J Vasc Surg 45(4):744-750

Cherr GS, Zimmerman PM, Wang J, Dosluoglu HH (2008) Patients with depression are at increased risk for secondary cardiovascular events after lower extremity revascularization. J Gen Intern Med 23(5):629-634
Elderon L, Whooley MA (2013) Depression and cardiovascular disease. Prog Cardiovasc Dis 55(6):511-523

Fowkes FG, Rudan D, Rudan I et al (2013) Comparison of global estimates of prevalence and risk factors for peripheral artery disease in 2000 and 2010: a systematic review and analysis. Lancet 382(9901):1329-1340

Lichtman JH, Bigger JT Jr, Blumenthal JA et al (2008) Depression and coronary heart disease: recommendations for screening, referral, and treatment: a science advisory from the American Heart Association prevention Committee of the Council on cardiovascular nursing, council on clinical cardiology, council on epidemiology and prevention, and interdisciplinary council on quality of care and outcomes research: endorsed by the American Psychiatric Association. Circulation 118(17):1768-1775

McDermott MM, Greenland P, Guralnik JM et al (2003) Depressive symptoms and lower extremity functioning in men and women with peripheral arterial disease. J Gen Intern Med 18(6):461-467

McDermott MM, Guralnik JM, Tian L et al (2016) Incidence and prognostic significance of depressive symptoms in peripheral artery disease. J Am Heart Assoc 5(3):e002959

Ramirez JL, Drudi LM, Grenon SM (2018) Review of biologic and behavioral risk factors linking depression and peripheral artery disease. Vasc Med In Press

Ruo B, Liu K, Tian L et al (2007) Persistent depressive symptoms and functional decline among patients with peripheral arterial disease. Psychosom Med 69(5):415-424

Smolderen KG, Aquarius AE, de Vries J, Smith OR, Hamming JF, Denollet J (2008) Depressive symptoms in peripheral arterial disease: a follow-up study on prevalence, stability, and risk factors. J Affect Disord 110(1-2):27-35

Wattanakit K, Williams JE, Schreiner PJ, Hirsch AT, Folsom AR (2005) Association of anger proneness, depression and low social support with peripheral arterial disease: the atherosclerosis risk in communities study. Vasc Med 10(3):199-206

\section{Submit your manuscript to a SpringerOpen ${ }^{\circ}$ journal and benefit from:}

- Convenient online submission

- Rigorous peer review

- Open access: articles freely available online

- High visibility within the field

- Retaining the copyright to your article

Submit your next manuscript at $\boldsymbol{\nabla}$ springeropen.com 